\title{
Lusioersily
}

\section{Multi-analyte study of circulating cytokines in smokers, with or without chronic obstructive pulmonary disease, and with or without lung cancer, using biochip array technology}

Duncan, M. W., Gibson, D. S., Bunn Jr, P. A., Spreafico, A., Baron, A. E., Wagner, B., Miller, Y. E., Toner, V., McConnell, I., Lamont, J. V., \& Fitzgerald, P. S. (2010). Multi-analyte study of circulating cytokines in smokers, with or without chronic obstructive pulmonary disease, and with or without lung cancer, using biochip array technology. In Cytokine (1-2 ed., Vol. 52, pp. 95). Elsevier. https://doi.org/10.1016/j.cyto.2010.07.404

Link to publication record in Ulster University Research Portal

Published in:

Cytokine

Publication Status:

Published (in print/issue): 04/09/2010

DOI:

10.1016/j.cyto.2010.07.404

Document Version

Publisher's PDF, also known as Version of record

\section{General rights}

Copyright for the publications made accessible via Ulster University's Research Portal is retained by the author(s) and / or other copyright owners and it is a condition of accessing these publications that users recognise and abide by the legal requirements associated with these rights.

\section{Take down policy}

The Research Portal is Ulster University's institutional repository that provides access to Ulster's research outputs. Every effort has been made to ensure that content in the Research Portal does not infringe any person's rights, or applicable UK laws. If you discover content in the Research Portal that you believe breaches copyright or violates any law, please contact pure-support@ulster.ac.uk. 
with receptor binding IL- $1 \alpha$ and IL- $\beta$ and there are nine IL- 1 receptors widely distributed in tissues. Polymorphisms in cytokines has been described to associated with different pathologies and some of them have been correlated with enhance or diminished the production of this molecules. The aim of this study is to determinate the association between polymorphisms in genes of the family members of the IL- 1 and cervical cancer. Polymorphisms of IL- $1 \alpha-889$ C/T, IL- $\beta-511$ C/T, +3962 T/C, IL$1 \mathrm{R}$ Pstl1970 C/T and IL-1RA mspa1 11100 was determinate in 19 healthy women and in 50 women with cervical cancer from the Occident of Mexico. We found statistical differences in IL- $1 \alpha-889 \mathrm{C} / \mathrm{T}$, with a higher frequency of the allele $\mathrm{T}$ in cervical cancer women compared with healthy controls, with a $p=0.0199$, and $O R$ of 4.099 and CI 95\% 1.161-14.47; beside we found the CC genotype predominantly in healthy women $p=0.0255$ and CT genotype with $p=0.0481$ than women with cervical cancer We did not found statistical differences in the others polymorphisms. The T allele of IL-1 -889 has been implicated in the increase of the expression and production of this cytokine in different studies and could participate in the chronic inflammation that has been associated with the progress to cervical cancer.

\section{doi:10.1016/j.cyto.2010.07.402}

\section{Chemokines}

PS3-64

The role of CCL5/RANTES in regulating nutrient receptor trafficking, metabolism and protein expression in activated $T$ cell

Olivia Chan ${ }^{1}$, Thomas T. Murooka ${ }^{1,2}$, Eleanor N. Fish ${ }^{1,3},{ }^{1}$ Department of Immunology, University of Toronto, Ontario, ${ }^{2}$ The Center for Immunology and Inflammatory Diseases, Massachusetts General Hospital, Charlestown, MA, ${ }^{3}$ Division of Cellular Molecular Biology, Toronto General Hospital Research Institute, Toronto, Ontario

Recruitment of effector $\mathrm{T}$ cells to sites of infection is imperative for an effective adaptive immune response. The inflammatory chemokine CCL5/RANTES activates its cognate receptor, CCR5, to initiate a number of cellular functions, including proliferation, chemotaxis, cytokine production, and apoptosis. We have shown that CCL5/ CCR5 signaling activates the mTOR/4E-BP1 pathway to directly modulate mRNA translation. Moreover, CCL5-mediated mTOR activation influences T cell chemotaxis by initiating the translation of chemotaxis-related proteins, including MMP-9 and cyclin D1. Up-regulation of chemotaxis-related proteins may "prime" $T$ cells for efficient migration. It is now clear that mTOR is a central regulator of cell size, nutrient sensing and glycolysis. In continuing studies, we are investigating the ability of CCL5 to regulate $\mathrm{T}$ cell metabolism through the $\mathrm{PI}-3^{\prime} \mathrm{K} / \mathrm{mTOR}$ pathway. Data generated in ex vivo activated human T cells show that CCL5 treatment, at doses that invoke chemotaxis, induces the activation of nutrient sensing kinase AMPK and key glycolytic metabolites including GSK-3 $\beta$. This suggests that CCL5 may be up-regulating ATPconsuming pathways and modulating glycolysis. Flow cytometry data show that CCL5 is also able to up-regulate the expression of amino acid transporter CD98, while having no effects on glucose transporter, Glut-1. In addition, using a radio-labelled glucose, we provide evidence for glucose uptake mediated by CCL5 treatment. Finally, inhibition studies with a glucose analogue, 2-deoxy-D-glucose, we demonstrate reduced CCL5-mediated $\mathrm{T}$ cell chemotaxis in a dose-dependent manner. Viewed altogether, these findings suggest that CCL5, at concentrations that support optimal chemotaxis, may also influence the metabolic status of activated $\mathrm{T}$ cells.

doi:10.1016/j.cyto.2010.07.403

\section{PS3-65}

Multi-analyte study of circulating cytokines in smokers, with or without chronic obstructive pulmonary disease, and with or without lung cancer, using biochip array technology

Mark W. Duncan ${ }^{1}$, David S. Gibson ${ }^{1}$, Paul A. Bunn Jr. ${ }^{2}$, Anna Spreafico ${ }^{2}$, Anna E. Barón $^{3}$, Brandie Wagner ${ }^{3}$, York E. Miller ${ }^{4}$, Vicki Toner ${ }^{5}$, Ivan McConnell ${ }^{5}$, John V. Lamont $^{5}$, S.P. FitzGerald ${ }^{5}$, ${ }^{1}$ Division of Endocrinology, Metabolism E Diabetes, Department of Medicine, ${ }^{2}$ Division of Medical Oncology, Department of Medicine,

${ }^{3}$ Department of Biostatistics and Informatics, Colorado School of Public Health, ${ }^{4}$ Division of Pulmonary Sciences/Critical Care Medicine, Department of Medicine, University of Colorado Denver, Aurora Colorado 80045 USA, ${ }^{5}$ Randox Laboratories Limited, 55 Diamond Road, Crumlin, Co. Antrim, United Kingdom

Cytokines are naturally occurring small regulatory proteins produced by various cell types. They act as external controlling elements in haematopoiesis and also mediate and control immune and inflammatory responses. Changes in cytokine levels have been reported in chronic obstructive pulmonary disease (COPD), a common inflammatory disease of the airways. Similarly, changes in circulating cytokine levels have been reported in other pulmonary disorders including lung cancer, but the specific nature of these changes is poorly defined. Because cytokines normally function as part of a complex interacting network, the use of a multiplexed approach for their deter- mination is important. Biochip array technology enables such an approach and can generate a cytokine profile from a single sample, at a single point in time. The aim of this study was to determine twelve cytokines simultaneously in the plasma of non-smokers and smokers with or without COPD and with or without lung cancer using Evidence biochip array technology. The cytokines IL- $1 \alpha$, IL-1 $\beta$, IL-2, IL-4, IL-6, IL-8, IL-10, VEGF, IFN $\gamma$, EGF, MCP-1 and TNF $\alpha$ were quantified by simultaneous chemiluminescent immunoassays on the biochip array. The biochip represents the solidphase and the vessel where the immunoreactions take place in discrete test sites. The Evidence analyzer was used for all determinations. Serum samples from 55 non-smokers, 54 smokers without COPD and 48 smokers with COPD were analyzed. The Kruskal-Wallis test with a false discovery rate (FDR) of 0.10 was used to identify cytokines that were differentially expressed across the 5 groups. For the cytokines that met the FDR criterion, post-hoc comparisons were made using Dunn's method with a family-wise error rate of 0.05 .

Four cytokines appeared to be differentially expressed across groups: IL-6, IL-8, VEGF and MCP1. Results of the post-hoc pairwise comparisons suggest plasma cytokine levels are significantly different between the following groups: non-smokers $v s$. adenocarcinoma (IL-6, IL-8); non-smokers vs. squamous cell cancer (IL-6, IL-8, VEGF); non-smokers vs. smokers with COPD (MCP1); smokers without COPD vs. adenocarcinoma (IL-6); smokers with COPD vs. squamous cell carcinoma (IL-6); smokers without COPD vs. squamous cell carcinoma (IL-6, IL-8, VEGF) and adenocarcinoma $v s$. squamous cell carcinoma (VEGF, IL-8). The biochip array enables the simultaneous assessment of 12 cytokines in a single sample and shows differences between several distinct clinical groups. This represents a valuable analytical approach for research in conditions involving the cytokines.

\section{doi:10.1016/j.cyto.2010.07.404}

\section{Methods of Cytokine Detection}

PS3-66

Milliplex $^{\mathrm{TM}}$ MAP multiplex immunoassays for simultaneous detection of human and mouse cytokines/chemokines

Yao Chen, Brandon Proctor, Jehangir Mistry, Qiang Xiao, Millipore Bioscience Division, St. Charles, MO 63304

Cytokine and chemokines are soluble proteins that exert a number of biological functions in both normal conditions and disease states such as metabolic disease, arthritis, sepsis, and cancer. Using Luminex's XMAP technology, we previously developed and commercialized the MILLIPLEX MAP Human Cytokine/Chemokine 42-plex Panel and Mouse Cytokine/Chemokine 32-plex panel, which allow the simultaneous measurement of 42 human cytokines or 32 mouse cytokines with minimal requirement of sample volume $(12.5 \mu \mathrm{l}-25 \mu \mathrm{l})$. Recently, we expanded our cytokine/chemokine portfolio with two new Human Cytokine Panels (Panel II: 23-plex; Pane III: 11-plex) and two new Mouse Cytokine Panels (Panel II: 12-plex; Panel III: 6-plex). Briefly, $25 \mu$ of neat (human) or 1:2 diluted (mouse) serum/plasma sample was incubated overnight at $4^{\circ} \mathrm{C}$ in a 96 -well filter plate with a mixed population of Luminex beads, each of which contains a unique fluorescent signature and covalently coupled with a specific capture antibody. After washing, the plate was incubated with $25 \mu \mathrm{l}$ biotinylated detection antibodies for $1 \mathrm{~h}$ and, subsequently, with $25 \mu \mathrm{l}$ streptavidin-phycoerythrin solution for $30 \mathrm{~min}$ at RT. Fluorescent signal of the beads was read using a Luminex 200 reader. Sample concentrations were calculated with 5-parameter logistic curve-fitting method. The analytical robustness of these assays is demonstrated by high accuracy (spike-recovery: 96-111\%) and good precision (intra-assay CV: $<10 \%$; inter-assay CV: $<16 \%$ ).These new MILLIPLEX MAP panels are highly sensitive and display no significant cross-reactivity within each panel. In addition, the assays were validated in normal serum/plasma, sepsis serum, and LPS-challenged PBMC tissue culture supernatant samples. In summary, our MILLIPLEX MAP cytokine multiplex assays are specific, accurate, reproducible and user-friendly. The availability of these assays provides useful tools for the investigation of biological functions of cytokines/ chemokines in various diseases.

doi:10.1016/j.cyto.2010.07.405

\section{PS3-67}

High dynamic range (HDR) immunoassay for the multiple simultaneous quantification of cytokines

Chris Lyman, Abby Tyler, Quansys Biosciences

The need for both high throughput immunoassays and immunoassays which can measure broad ranges of analyte is increasing. Traditionally, immunoassays must be built to focus on either sensitivity or the ability to quantify high analyte concentrations. Rarely have there been assays which can achieve high sensitivity while maintaining the ability to quantify high analyte concentrations. Faced with these limitations, researchers have had to test multiple dilutions of their sample to ensure 